\title{
Changing Paradigms in Pomegranate Breeding: A Review
}

\author{
Akanksha Sharma*, R. K. Dogra, Gopal Singh and Suman Bodh \\ Department of Fruit Science, Dr YS Parmar University of Horticulture and Forestry Nauni, \\ Solan, Himachal Pradesh173 230, India \\ *Corresponding author
}

\section{A B S T R A C T}

\begin{tabular}{|l|}
\hline K e y w o r d s \\
Pomegranate, \\
Breeding methods, \\
Polyploidy, \\
Mutation and \\
Paradigm shift
\end{tabular}

\begin{abstract}
Pomegranate (Punica granatum L.) is one of the important fruit crop of arid and semiarid regions of the world belongs to family Punicaceae. This fruit crop is often cross pollinated, genetically heterozygous and appropriate natural variation is present. Traits like reducing the size of the plant in order to increase orchard plant density, selecting self fertile genotypes to maintain a higher consistent yield over time and selecting genotypes with higher nutritional value of the fruit are important for ideotype plant in pomegranate. Its genetic improvement poses various obstacles, such as long juvenile period, frequent inter and intra-species incompatibility, high heterozygosity, sterility and the presence of specific traits only in wild species. These characteristics make breeding techniques difficult, expensive and time consuming. This explains why some fruit crops have been improved almost exclusively with clonal selection, using variability from spontaneous mutations or selecting plants derived from natural hybridization. Some novel biotechnological techniques coupled with traditional methods of breeding are being used now a days, which has resulted in paradigm shift for its improvement.
\end{abstract}

\section{Introduction}

Pomegranate is one of the world's most ancient, beloved plant and fruit. It has been cultivated since ancient times throughout the Mediterranean region. The derivation of word pomegranate comes from the Medieval Latin "pomum granatum" meaning apple of many grains or seeds. As a fruit with many seeds, the pomegranate is the representative of fertility. Pomegranate is having wide geographic distribution across several continents despite that very little information is available about its genetic origin and centres of diversity (Still, 2006). The family of this fruit consists of a single genus Punica along with two species namely $P$. granatum and $P$. protopunica. Cultivation of wild pomegranate is carried out at Transcaucasia and Central Asia from Iran and Turkmenistan to Northern India (Chandra et al., 2010). It is assumed that Punica protopunica played a role in the origin of pomegranate cultivars. The species granatum has two subspecies viz. Prophyrocarpa and Chlorocarpa. The scientific findings corroborate traditional usage of the pomegranate as a medical remedy and indicate that the tissues of 
pomegranate fruit, flowers, bark, and leaves contain bioactive phytochemicals that are antimicrobial, reduce blood pressure, and act against serious diseases such as diabetes and cancer. These findings have led to a higher awareness of the public to the benefits of the pomegranate fruit, and consequently to a prominent increase in the consumption of its fruit and juice. In recent times it has emerged as a commercial fruit crop. Pomegranate is an often-cross pollinated fruit crop and have good seed germination ability. As a result, over the years large number of various seedling forms has evolved in nature in different regions of the world (Levin, 1995). There are very few varieties that have been developed by systematic breeding programmes. Cytological study of a crop is very useful for planning breeding programme. According to Smith (1976), the cultivated species of pomegranate has chromosome number $2 n=2 x=16, \quad 18$. The somatic chromosome number of some of the cultivated varieties is $2 n=16$ whereas, the 'Double Flower' having chromosome number $2 n=18$. According to Mars (2000) there are so many problems still faced by pomegranate growers and different methods of cultivar improvement and management of genetic resources is the need of hour. Since there is increasing demand for pomegranate because of its superior pharmacological and therapeutic properties and also to meet the demands of local and international consumers, processors, growers and exporters well planned breeding efforts are required for the development of superior cultivars.

\section{Breeding Objectives}

The major objectives of pomegranate breeding are as follows: High productivity, dwarfing habit, frost resistance, good fruit quality, softseedness, resistance to fruit cracking, resistance to fruit borers, resistance to bacterial blight and good post-harvest quality.

\section{Activities in crop improvement}

The desired changes in genotypes of crop species and the consequent benefits to farmers are brought about by a series of interrelated and largely interdependent activities. Uncontrolled hybridization in farmer's field as well as with wild relatives and/or progenitors occurring in the natural habitat, most likely increased the variation in the germplasm available to early farmers. Over many centuries, the conscious and unconscious selecting by farmers, along with selective pressures imposed by the temporal and spatial heterogeneity of the growing conditions, resulted in landraces, genetically heterogeneous populations that are locally adapted to the conditions imposed by man and the physical environment.

The process of crop improvement by farmers' selection, however was a very slow process compared with science-based professional plant breeding. Until the beginning of the $20^{\text {th }}$ century, controlled hybridization to create novel variation available for selection was rarely involved.

The rediscovery of Mendel's work at the turn of century provided a solid scientific basis for plant breeding. The awareness of the particulate nature of hereditary factors and the possibility to create novel combinations of traits by hybridization, mutation and polyploidy contributed enormously to the professional seedmanship of the $20^{\text {th }}$ century.

The recent integration of advances in biotechnology, genomic research and molecular marker applications with conventional plant breeding practices has created the foundation for molecular plant breeding, an interdisciplinary science that is revolutionizing $21^{\text {st }}$ century crop improvement. 


\section{Introduction}

Introduction is a crop improvement method in which genotypes or group of genotypes taking to new places, where it is not cultivated before the introduction from the place of cultivation. In 1905, varietal improvement programme was started at Ganesh Khind Fruit Research Station, Pune. Five local introduced varieties along with two exotic varieties, Kabul and Muscat were grown from seeds of selected fruits.

The seedling population of Dholka and Alandi were found to show variation with respect to bearing habit, fruit size, juice colour, quality and fruit yield. Later on indigenous and exotic varieties collection was made at Ganesh Khind Fruit Research Station, Pune in 1944. At different centres of All India Co-ordinated Research Project on arid zone fruits, more than 60 varieties including both exotic and indigenous are being evaluated. Introductions namely Chokab, Ras-el-Baghi, Roman, Sellimi, Suffami and Wellingi failed to establish under warm climatic conditions of India due to their deciduous nature.

Some other introductions like Gulsha Red, Gulsha Rose Pink and Shirin Anar also showed the same behaviour. Whereas, some introduced cultivars like Gulsha Red Pink, Gulsha Red, Appuli, Lupania, Kandhari, Khog and Bedana are being utilized in breeding programmes to induce dark red aril colour (Pareek and Sharma, 1993).

Some newly introduced commercial cultivars were wonderful from USA; Sirin, Post Sephid, Males, Agha Mohammad Ali, Be Hastah, Alah from Iran; Rannyiz G-1-3-34, Rannyiz G-1-8-23, Cherenyj G-1-8-7 from Tunesia (Singh and Rana, 1993). At Hisar, Shirin Anar and Russian seedling were found to have resistance against bacterial leaf spot.

\section{Selection}

Many cultivars have been developed through selection (clonal and seedling). Due to the variability and adaptability to the present agro-climatic conditions, the superior genotypic selection is the approach to get desirable lines. Because of heterozygosity seed exhibit variation, making selection of desirable plant traits possible. Hence, seedling selection has a great significance in the pomegranate breeding (Jalikop and Kumar, 1998). Pomegranate selections are made on the basis of flower, rind and aril colour, fruit size, sugar and acid contents, resistance to biotic and abiotic stresses, yield, keeping quality, seed hardiness, etc. (Holland et al., 2009). Numerous varieties have been evolved in different pomegranate cultivating regions and multiple varieties have advanced in discrete pomegranate growing regions by means of simple selection. Cultivar GBG-1 is a selection from openly pollinated population of Alandi in 1932. The names were generally given either on the basis of colour of fruit or place of its cultivation. Early ripening cultivar known as Emek in Israel, selected from seedlings that are raised from open pollinated seeds. Kamel a selection is a kin to Wonderful, used for dark red skin colour appeared earlier than in Wonderful (Holland et al., 2007). Zaoxuan 018 a chance seedling selected by Chinese workers (Wang et al., 2006) from Dahongpao and Zaoxuan 027 was selected from Daqinpi. Two of the main commercial export cultivars from India, Mridula and Bhagwa, are the result of a selection from progenies of a cross between Ganesh and the red Gul Shah Red pomegranate cultivar from Russia (Mahatma Phule Agricultural University 2007). Mridula and Bhagwa combine the red skin color, seed softness, and evergreen habit of growth from their parents. Ganesh itself is an evergreen selection from Alandi (Jalikop, 2003) that produces a soft-seeded fruit with poor fruit 
quality. Ganesh a soft seeded Indian cultivar is most acclaimed selection raised from Alandi, a hard seeded seedling population and later on G-137 was selected from an openpollinated progeny of Ganesh. An elevated degree of disparity was observed for fruit characters by Ramu et al., 1996 in the seedling population of Alandi. With the exception of aril color acceded by Indian workers Wavhal and Choudhari (1985), the selections from Muscat were more encouraging as compared to Ganesh. Plants that are propagated through seeds possess a deep tap root system, providing good anchorage and moisture from deeper layers of the soil. Therefore, Jalikop and Kumar (1993) undertook to develop an inbred line of Ganesh created by selfing repeatedly for generations intended for plants to attain homozygosity for the traits of interest that can be seedpropagated.

\section{Hybridization}

Breeding of pomegranate is comparatively easier than other fruit crops, because of the presence of larger flower size resulting in convenient hybridization, and fruits produced are with abundant seeds, that germinates well, with the relatively shorter juvenile phase. Our native cultivars are devoid of blood red colour present in exotic types such as Shirin Anar, Gulsha Rosa Pink and Gule Shah. To pervade this trait into Ganesh crosses were made at Rahuri in 1976. In order to develop colored variety, Russian cultivars were employed as they produce dark red arils along with red fruit skin but hard seeds and small acidic fruits are produced and does not thrive well under Indian tropical climate (Purohit, 1982). Since very little is known on the heritability of desirable traits in pomegranates, few experiments were conducted to study the inheritance of some important features, such as acidity, seed hardness, and aril color. Breeding of pomegranates in India was done for disease resistance (Jalikop et al., 2005; Jalikop et al., 2006), low acidity and high fruit quality under hot arid environment (Samadia and Pareek, 2006); fruit yield (Manivannan and Rengasamy, 1999); juice production (Jalikop and Kumar, 1998); aril color (Wavhel and Choudhari, 1985); fruit weight, flesh color, seed size, and juice content (Karale et al., 1979); TSS (Choudhari and Shirsath, 1976); and seed softness (Jalikop and Kumar, 1998). From crosses between Daru and Ganesh or Daru and Ganesh progenies, it was found that high acidity was always dominant to low acidity, pink aril color was dominant to white color, and hard-seeded nature was dominant to soft (Jalikop et al., 2005). Daru was used as a parent in breeding pomegranate cultivars tolerant to bacterial nodal blight (Xanthomonas campestris pv. parthenii). These authors indicated that the resistance to bacterial nodal blight is controlled by recessive genes (Jalikop et al., 2005). For many fruit attributes, soft and semisoft seeded pomegranate cultivars share similarities, whereas hard-seeded pomegranates are distinctively different (Jalikop and Kumar 1998). For example, the hard-seeded cultivars as a group had significantly higher fruit weight and volume than semisoft and softseeded pomegranates. Soft-seeded pomegranates were recommended by Jalikop and Kumar (1998) as parents for developing high-juice cultivars due to their significantly higher content of juice. Karale and Desai (2000) measured heterosis for fruit characters manifested by the individual hybrids over mid parental value. They found that heterosis values were maximal for juice weight and aril weight percentage. Inheritance of fruit characteristics such as skin and aril color, taste and seed softness was studied using several combinations of crosses between the cultivars Fellahyemez, Ernar, and Hicaznar (Ataseven and Celik, 2006). Hybrid seedlings with good frost resistance were achieved 
following successive crosses (Levin, 2006). In China, several pomegranate cultivars have been obtained by breeding. These include the early-ripening Yushiliu 4 (Zhao et al., 2006), the soft-seeded Hongmanaozi (Zhao et al., 2007), good-quality fruit Zaoxuan 018 and Zaoxuan 027 (Wang et al., 2006). A breeding project in Israel was initiated in 2002 to exploit the principal advantages of the Israeli cultivars: early ripening, good color, and soft seeds. In addition, appealing skin and aril color (particularly bright red color) were desirable features. Breeding was initiated by selecting seedlings from open pollination of known cultivars. So far, the cultivar Emek was released from screening these populations. Emek is a very early cultivar that ripens in mid-August. It has a pink-red skin and bright red arils. The seeds are soft and the taste is sweet and low acid. Emek ripens earlier than Shani-Yonay (Holland et al., 2007), and its average weight is higher than Shani-Yonay.

\section{Polyploidy}

An organisms or individual having more than two basic or monoploid sets of chromosomes is called polyploidy and such condition is known as polyploidy. It is one of the best known natural forces of evolution and most rapid method of producing radically different but vigorous and well adapted genotypes. Shao et al., (2003) obtained tetraploid plants in pomegranate (Punica granatum L. var. 'Nana') by colchicine treatment of shoots propagated in vitro. Shoots cultured on MS medium supplemented with $10 \mathrm{mg}$ 1-1 colchicine, $1.0 \mathrm{mg} \mathrm{1-1} \mathrm{BA} \mathrm{and} 0.1 \mathrm{mg} \mathrm{1-1}$ NAA for 30 days produced tetraploids at a high frequency of $20 \%$. No tetraploids were detected by treating the shoots in $5000 \mathrm{mg} \mathrm{1-1}$ colchicine for $114 \mathrm{~h}$. Shoots treated by 5000 mg 1-1 colchicine for 96h produced three morphological mutants with narrow leaves, which were later confirmed as mixoploids that separated into diploids and tetraploids after further subculture. In vitro tetraploids plants had shorter roots, wider and shorter leaves than the diploid ones. Tetraploid pomegranate plants grew and flowered normally in pots, but possessed flowers with increased diameter and decreased length compared to diploids. The number of pollen grains per anther was higher in tetraploids, but the viability of pollen decreased significantly.

\section{Mutation}

Though mutation breeding is useful tool to generate variability, but it requires raising a large population to identify a desirable type. It is a 'hit and miss' method to get desirable mutant. Also, majority of the mutants are generally recessive that are of little or no use, making the technique less approachable. Perchance, the reason for conducting limited experiments in pomegranate with adversity. Seeds and cuttings exposed to Gamma $(\gamma)$ radiations, with 1-40 kR and selected types that outrun the initial material in terms of fruit yield, size and quality. Varieties bearing sweet fruit were more sensitive to radiation as compared to acid-sweet or acid fruit. (Akhund- zade et al., 1977) studied effects of irradiation on cuttings, seeds and pollen and observed a wide variability at 5-10 kR doses. In China, varieties like Hongma-naozi, Taihanghong and Hongyushizi were isolated as natural mutants (bud sports) from the different varieties. Levin (1990) treated pomegranate seeds with chemical mutagens and x-rays and acquired forms possesing good fruit, quality of juice and good keeping quality. Best results were seen with x-rays at 10-20 kR. Assuring mutants were also bred by $\mathrm{N}, \mathrm{N}$-dimethyl $\mathrm{N}$-nitrosourea treatment and the most promising forms produced was the soft seeded seedling Sverkhrannil (meaning super-early). Chemical mutagenesis approach in pomegranate breeding was also 
used (Shao et al., 2003; Matuskovic and Micudova, 2006).

\section{Biotechnological tools}

Biotechnology may be defined as 'the controlled use of biological agents, such as, microorganisms, or cellular components, for beneficial use'.

\section{Genetic transformation}

To date, the different horticultural traits that have been targeted for improvement by genetic transformation are the control of pests and diseases in pomegranate. Terakami attempted genetic transformation in a dwarf pomegranate species, var. 'Nana'. In vitro regenerated adventitious shoots derived from leaf segments were inoculated with $A$. tumefaciens strain EHA105 harbouring the binary vector pBin19-sgfp, containing neomycin phosphotransferase (nptII) and green fluorescent protein (gfp) gene as a selectable and visual marker, respectively.

After co-cultivation, the inoculated adventitious shoots were cut into small pieces to induce regeneration, and then selected on MS medium supplemented with 0.5 M NAA, $5 \mathrm{M}$ BA, $0.3 \%$ gellangum, $50 \mathrm{mg} / \mathrm{l}$ kanamycin and $10 \mathrm{mg} / \mathrm{l}$ meropenem. Putative transformed shoots were regenerated after 6-8 months of selection. PCR and PCR-Southern blot analysis revealed the integration of the transgene into the plant genome.

Transformants bloomed and bore fruits within 3 months of potting, and the inheritance of the transgene was confirmed in $\mathrm{T} 1$ generation. The advantage of the transformation of dwarf pomegranate was shown to be the high transformation rate, which can successfully be exploited in other desirable genotypes with any desirable traits.

\section{Marker technology}

Morphological, biochemical and molecular markers have been extensively used to assess genetic diversity in pomegranate and are thus useful for germplasm management by removing redundant germplasm. Till now, only a single report of transgenic development in a dwarf ornamental pomegranate (Punica granatum L.var. nana) have made (Terakami et al., 2007). Several attempts were made for the regeneration of the plant by employing the leaf (Omura et al., 1987) and shoot tip explants (Mahishni et al., 1991). Enzyme based marker was employed to identify the genetic variation within the existing genotypes. Somatic embryogenesis was also practiced by using petal as an explant (Nataraja and Neelambika, 1996). Casteels et al., (1990), abaecin was identified, i.e. a major antibacterial response to peptide's broad spectrum; specifically lower activities against Gram- negative plant pathogens and its lack of bacterial inhibition at medium ionic strength differs from the apidaecins. Moreover, frequently noted activity was against a Xanthomonas strain that is apidaecin - resistant. Zeatin riboside (ZR) was reported to be responsible for inducing bud break and proliferation of axillary shoot observed in mature nodal segments of an elite cultivar Ganesh (Naik et al., 1999). Multiple growth enhancers such as casein hydrolysate $(\mathrm{CH})$; (Mascarenhas et al., 1981), coconut water (CW); (Sharon and Sinha, 2000) or adenine sulfate (AS), are proven useful and are cultivar specific.

The addition of adsorbents, such as PVP or activated charcoal aided development of shoot. Poor germination rate is one of the major drawbacks to profitably utilizing somatic embryogenesis in pomegranates; Therefore, high germination rate upto $80-85$ $\%$ is required to make the economic application of somatic embryogenesis 
successful (Rout et al., 2006). In pomegranate, zygotic embryos (mature/immature) from fruits (ripe/unripe) respectively have been exploited for inducing somatic embryogenesis (Kanwar et al., 2010).

\section{Problems in Pomegranate Breeding}

Traits like reducing the size of the plant in order to increase orchard plant density, selecting self fertile genotypes to maintain a higher consistent yield over time and selecting genotypes with higher nutritional value of the fruit also need to be considered in breeding depending on the fruit crop that is dealt with. Genetic improvement of most species of fruit crop poses range of obstacles. These include the long juvenility period of some species, frequent inter and intra-species incompatibility, high heterozygosity, sterility and the presence of specific traits only in wild species. These characteristics make breeding techniques difficult, expensive and time consuming. This explains why some fruit crops have been improved almost exclusively with clonal selection, using variability from spontaneous mutations or selecting plants derived from natural hybridization. Recent molecular and biotechnological approaches such as somaclonal variation, gene transformation or protoplast technology provide the potential for making significant changes to varieties, but limited progress has been made in this fruit crop. Such targets can be met by systematic well planned breeding programmes either by conventional or with the help of biotechnological approaches (Shukla et al., 2004).

\section{Future Prospects}

Pomegranate culture is still affronted to many problems that modern breeding programmes must resolve. The future of this fruit depends on the selection of high quality cultivars with soft seeds and resistant to cracking, fruit borer and bacterial blight. The direct use of existing cultivars and 'wild types' may be more effective than new hybridization. Further prospecting, collection, evaluation and selection of local material need to be carried out. Plant material inter change should be promoted at regional and international level. Enactment of Indian pomegranate takes place every now and then by many workers based on various morphological traits like, flower, fruiting pattern, appropriate fruit size, colour, aril colour, taste, juiciness, sugar content, acidity and tannin content of rind (Singh et al., 2019). A thorough screening of pomegranate germplasm is essential to identify resistant genotypes using biotechnological tools and improve them for other desirable traits through genetic engineering. Scientists should resort to mutation breeding when trait of interest is not present in the natural gene pool. Little is known about the mechanisms and sources of disease resistance in pomegranate, so extensive molecular and genomic studies are needed. Genetic manipulations aimed to increase shelf life, cold tolerance, and resistance against latent pathogens during storage could be quite valuable. Progress is also needed in the areas of genomics and gene mapping, which have lagged behind those in other fruit species.

\section{References}

Akhund-zade, I. M., E. E. Fedorova, G. M. Mamedov and Iskenderova, Z. D. 1977. Study of the cytogenetic characteristics of pomegranate. Ispolz-biofiz-meto-dov-v-genet-selektsioneksperimente. 17: 8-9.

Ataseven, E., and Celik, M. 2006. Similarities between pomegranate parents and crosses regarding some fruit characteristic. 1st International Symposium on Pomegranate and Minor Mediterranean Fruits, 16-19 
October 2006; Adana, Turkey, pp. 229-232.

Casteels, P., A. L. Christophe, L. Riviere, J. V. Damme, C. Elicone and Fleming M. 1990. Isolation and characterization of abaecin, a major antibacterial response peptide in the honeybee. European Journal of Biochemistry. 187: 381-386.

Chandra, R., K. D. Babu, V. T. Jadhav and Teixeira da Silva. 2010. Origin, History and Domestication of Pomegranate. Fruit Vegetable and Cereal Science and Biotechnology. 4: 1-6.

Choudhari, K.G., and Shirsath, N.S. 1976. Improvement of pomegranate (Punica granatum L.) by selection. South Indian Horticulture. 24(2):56-59.

De Candolle A. 1967. Origin of Cultivated Plants. Hafner Publishers Co., New York, pp. 468.

Holland, D., K. Hatib and Bar-Ya'akov I. 2009. Pomegranate: Botany, horticulture, breeding. In: Janick J (Ed) Horticultural Reviews (Vol 35), John Wiley and Sons, New Jersey, pp 127191.

Holland, D., K. Hatib, I. Bar-Yaakov, E. Yonay and El-Hadi F.A. 2007. ShaniYonay pomegranate. Horticultural Science. 42: 710-711.

Jalikop, S. H., and Kumar, PS. 1993. Seed propagation, inbred production and breeding method in pomegranate (Punica granatum L.). National Symposium in Plant Breeding Strategies for India, $2000 \mathrm{AD}$ and beyond, Aurangabad, India. pp. 25-27.

Jalikop, S. H., and Kumar, P.S. 1998. Use of soft, semisoft and hard -seeded types of pomegranate (Punica granatum) for improvement of fruit attributes. Indian Journal of agricultural Sciences. 68 (2): 87-91.

Jalikop, S. H., P. S. Kumar, R. D. Rawal and
Kumar R. 2006. Breeding pomegranate for fruit attributes and resistance to bacterial blight. Indian Journal of Horticulture. 63(4): 352358.

Jalikop, S. H., R. D. Rawal and Kumar R. 2005. Exploitation of sub-temperate pomegranate Daru in breeding tropical varieties. Acta Horticulturae. 696: 107112.

Jalikop, S. H., R. D. Rawal, R. H. Laxman and Kumar R. 2003. Scope for gene exchange between cultivated and decorative pomegranates. National Seminar on Advances in Genetics and Plant Breeding- Impact of DNA Revolution, October 30-31, 2003, University of Agricultural Sciences, Dharwad, India 103pp.

Kanwar, K., J. Joseph and Deepika, R. 2010. Comparison of in vitro regeneration pathways in Punica granatum L. Plant Cell Tissue and Organ Culture. 100: 199-207.

Karale, A. R., and Desai, U. T. 2000. Study of heterosis for ffruit characters in inter cultivar crosses of pomegranate (Punica granatum L.). Indian Journal of Genetics and Plant Breeding. 60(2):191-196.

Karale, A. R., K. U. Sanghavi and Patil, A. V. (1979). Improvement of pomegranate (Punica granatum L.) by seedling selection. Research Bulletin of Marathwada Agricultural University. 3(5):57-59.

Levin, G. M., 1990. Induced mutagenesis in pomegranate. Referativnyi Zhurnal. 10:33-99.

Levin, G. M., 1995. Aspects of pomegranate culture in Turkmenistan. Plant Genetic Resources Newsletter. 102: 29-31.

Levin, G. M., 2006. Pomegranate. $1^{\text {st }}$ edn. Third Millennium Publishing, East Libra Drive Tempe, AZ. 129p.

Mahishni, D. M., A. Muralikrishna, G. 
Shivashankar and Kulkarni R. S. 1991. Shoot tip culture method for rapid clonal propagation of pomegranate (Punica granatum L.). In: Horticulture- New technologies and application (Prakash J and Pierik RLM (eds)). Kluwar Academic Publisher, Dordrecht, Netherlands. pp. 215-217.

Manivannan, K., and Rengasamy, P. 1999. Genetic evaluation of certain parents and hybrids in pomegranate (Punica granatum $\mathrm{L}$.). Journal of the Andaman Science Association. 15: 64-68.

Mars, M., 2000. Pomegranate plant material: genetic resources and breeding, a review. Options Mediterraneennes. Serie A: Seminares Mediterraneens. 42: 55-62.

Mascarenhas, A. F., P. K. Gupta, V. M. Kulkarni, U. Mehta, R. S. Iyer, S. S. Khuspe and Jagannathan V. 1981. Propagation of trees by tissue culture. In: Proceedings of COSTED symposium on tissue culture of economically important plants, Rao AN ed. held at Singapore Institute of Biology, Bangalore. pp. 175-179.

Matuskovic, J., and Micudova, O. 2006. Practices with chemical mutagen (natrium azid) on growth habit Punica granatum L. p. 41. In: ISHS, 1st International Symposium, Pomegranate and Minor Mediterranean Fruits, Abstracts contributed papers, 16-19 Oct., Adana, Turkey.

Naik, S. K., S. Pattnaik and Chand, P. K. 1999. In vitro propagation of pomegranate (Punica granatum L. cv. Ganesh) through axillary shoot proliferation from nodal segments of mature tree. Scientia. Horticulturae. 79: $175-183$.

Omura, M., N. Matsuta, T. Moriguchi and Kozaki I. 1987. Adventitious shoot and plantlet formation from cultured pomegranate leaf explants.
Horticultural Science. 22(1): 133-134.

Pareek, O. P., and Sharma, S. 1993. Genetic resources of under exploited fruits. In: Advances in Horticulture. Vol 1. (Chadha KL and Pareek OP (eds.)). Malhotra Publishing House, New Delhi. pp. 189-225.

Purohit, A. G., 1982. Flower induction in deciduous pomegranate in tropics. Scientific Culture. 48: 146-47.

Ramu, B. S. S., P. N. Reddy, S. A. Hussain and Patil P. B. 1996. A new seedless selection from pomegranate $\mathrm{cv}$. 'Alandi'. Current Research, University of Agricultural Sciences, Bangalore. 25: 122-124.

Rout, G. R., A. Mohapatra and Jain, S. M. 2006. Tissue culture of ornamental pot plant: a critical review on present scenario and future prospects. Biotechnology Advances. 24: 531-560.

Samadia, D. K., and Pareek, O. P. 2006. Studies on genetic variability and varietal performance in pomegranate under hot arid environment. Haryana Journal of Horticultural Sciences. 35 (3/4): 196-199.

Shao, J., C. Chen and Deng, X. 2003. In vitro induction of tetraploid in pomegranate (Punica granatum). Plant Cell Tissue and Organ Culture. 75(3): 241-46.

Sharon, M., and Sinha, S. 2000. Plant regeneration from cotyledonary node of Punica granatum L. Indian Journal of Plant physiology. 5: 344-348.

Shukla, A. K., A. K. Shukla and Vashishtha, B. B. 2004. Fruit Breeding approaches and achievements. International Book Distributing Comp, Charbagh, Lucknow, U.P., pp. 342.

Singh, B. P., and Rana, R. S. 1993. Promising fruit introductions. In: Advances in Horticulture. Vol 1. [Chadha KL and Pareek OP (eds.)]. Malhotra Publishing House, New Delhi. pp. 4346. 
Singh, T.H., T. Gupta and Sharma, S. 2019. Development and purity identification of hybrids by using molecular marker in wild pomegranate (Punica granatum L.). Scientia Horticulturae. 247: 436-448.

Smith, P.M., .1976. Minor crops. In: Evolution of Crop Plants (Simmonds NW. (ed.)). Longman, London. pp. 207-214.

Still, D.W., 2006. Pomegranates: a botanical prospective. In: Pomegranates: Ancient Roots to Modern Medicine (Seeram NP, Schullman RN and Heber D (eds.)). CRC Press Taylor and Francis Group, Boca Raton, Florida. pp. 199-209.

Terakami, S., N. Matsuta, T. Yamamoto, S. Sugaya, H. Gemma and Soejima J. 2007. Agrobacterium -mediated transformation of the dwarf pomegranate (Punica granatum L. var. Nana). Plant Cell Reports. 26: 12431251.

Wang, Y., X. L. Yin and Yang, L. F. 2006. Breeding of Zaoxuan 018 and 027 pomegranate selections. China Fruits. 4: 6-8.

Wavhal, K. N., and Choudhari, K. G. 1985. Varietal improvement of pomegranate. Maharashtra Journal of Horticulture. 49-52.

Zhao, G. R., L. W. Zhu, S. M. Zhang, B. Jia and Li S. W. 2007. A new soft-seeded pomegranate variety, Hongmannozi. Acta Horticulturae Sinica. 34(1): 260.

Zhao ,Y. L., Y. Z. Feng, Z. H. Li and Cao Q. 2006. Breeding of new pomegranate cultivar "Yushiliu 4". China Fruits. 2: $8-10$.

\section{How to cite this article:}

Akanksha Sharma, R. K. Dogra, Gopal Singh and Suman Bodh. 2020. Changing Paradigms in Pomegranate Breeding: A Review. Int.J.Curr.Microbiol.App.Sci. 9(09): 1878-1887.

doi: https://doi.org/10.20546/ijcmas.2020.909.237 